\title{
Too individualistic for safety culture? Non-traffic related work safety among heavy goods vehicle drivers
}

\author{
Regine Grytnes ${ }^{\mathrm{a}, *}$, Hitomi Shibuya, Johnny Dyreborg ${ }^{\mathrm{b}, 1}$, Sisse Grøn ${ }^{\mathrm{c}, 2}$, Bryan Cleal ${ }^{\mathrm{d}, 3}$ \\ ${ }^{a}$ Department of Occupational Medicine, Regional Hospital of West Jutland, University Research Clinic, Gl. Landevej 61, 7400 Herning, Denmark \\ ${ }^{\mathrm{b}}$ National Research Centre for the Working Environment, Lersø Parkalle 105, 2100 Copenhagen, Denmark \\ ${ }^{\mathrm{c}}$ TeamArbejdsliv, Høffdingsvej 22, 2500 Valby, Denmark \\ 'Steno Diabetes Center A/S, Niels Steensens Vej 2-4, Denmark
}

\section{A R T I C L E I N F O}

\section{Article history:}

Received 16 June 2015

Received in revised form 4 February 2016

Accepted 17 April 2016

\section{Keywords:}

Non-traffic related work safety

Heavy goods vehicles

Mixed methods case study

Safety culture

\begin{abstract}
A B S T R A C T
Introduction: This article reports on a study of non-traffic related work safety among drivers of heavy goods vehicles in Denmark. In the heavy goods vehicle transport (HGV) sector only $6.4 \%$ of workplace accidents involving drivers are traffic related. HGV work is characterised by solitary work, as drivers tend to work at a physical distance from their own company and their working environment is also influenced by the working environment of other companies e.g. the places where they deliver goods. This study focuses on an analysis of HGV drivers' and managers' differentiated understandings of risk and safety and its management within an organisational context. The situational focus involves viewing HGV drivers' working environment as a part of the organisational structure as well as of other social relationships. An understanding of safety culture as practice is applied with the view of identifying values and attitudes as well as organisational and technical aspects in relation to how individualist or collectivist understandings of risk and safety influence the working environment in HGVs.

Method: The study applied a mixed methods approach and in this article the qualitative interviews conducted with drivers and managers is the primary data source.

Results: This study suggests a widespread understanding of drivers as being individually oriented in their work, from drivers and management alike. However, the study also demonstrates that, in conducting their work, the drivers are actually interdependent, and share knowledge frequently, albeit informally. The organisational structure of the company shapes their individual attitudes towards safety but they also report being dependent on relationships with, and information from, their fellow colleagues, former colleagues and friends who shape their understandings and attitudes towards hazards and safety practices. The analysis points to risk-taking and unsafe practices as prevalent among HGV drivers, who often refer to risk as trivial and the management of such risks as one's own responsibility. Knowledge of how to manage risks in everyday practice is shown to be principally related to personal experiences but also to the good advice and examples of fellow drivers.
\end{abstract}

\footnotetext{
The research was carried out at: Department of Occupational Medicine, Regional Hospital West Jutland and National Research Centre for the Working Environment, Denmark.

* Corresponding author at: Department of Occupational Medicine, Regional Hospital of West Jutland, Gl. Landevej 61,7400 Herning, Denmark. Tel.: +45 78433521 .

E-mail addresses: regine.grytnes@vest.rm.dk (R. Grytnes), hitomi.shibuya.dk@gmail.com (H. Shibuya), jdy@arbejdsmiljoforskning.dk (J. Dyreborg), sig@teamarbejdsliv.dk (S. Grøn), byac@steno.dk (B. Cleal).

1 Tel.: +4539165201 .

2 Tel.: +4538345034 .

3 Tel.: +4539680800 .
} 
Conclusions: The analysis points to interdependent and collectivist practices among HGV drivers even though they are perceived as being individualistically oriented when it comes to safety. Therefore, non-traffic related safety practices, in this case the loading and unloading of vehicles, occur in the grey zone of organisational safety management. Despite the fact that organisational safety initiatives are initiated, the management sees limited possibilities for enforcing them and hence safety practice is often left to the individual driver. Practical applications: A safety culture perspective might enhance work safety among HGV drivers if we are able to understand workplace culture in a pluralistic way. Collectivist practice among the drivers can be utilised in order to improve knowledge sharing and situational safety practices. The informal communication identified among the drivers might offer a new model for safety initiatives based on more collectivist, albeit informal, safety culture practices on behalf of HGV companies.

(c) 2016 Elsevier Ltd. All rights reserved.

\section{Introduction}

Non-traffic related work injuries among drivers of heavy goods vehicles (HGV) are consistently reported as being a challenge in the trucking industry across different countries (Edwards, Davey, \& Armstrong, 2014; Irvine, 1967; Leigh, Waehrer, Miller, \& Keenan, 2004; Shibuya, Cleal, \& Kines, 2010; Shibuya, Cleal, \& Mikkelsen, 2008; Shibuya, Hannerz, Mikkelsen, Cleal, \& Gubba, 2008; Smith \& Williams, 2014; Spielholz et al., 2008). While factors pertaining to traffic-related accidents and injuries affect the broader public (e.g. Adams-Guppy \& Guppy, 2003; Bunn, Slavova, Struttmann, \& Browning, 2005; Campagne, Pebayle, \& Muzet, 2004; Taylor \& Dorn, 2006) non-traffic related accidents impact upon the workplace health and safety of people working in the industry (Smith \& Williams, 2014). It is important to acknowledge that HGV drivers may cause others harm, yet the degree and extent of the harm resulting from traffic-related incidents does not mean that non-traffic related occupational safety incidents are a trivial issue. It has also been shown that the job-group in which HGV drivers are included has a heightened risk of disability retirement resulting from occupational injury (Hannerz, Mikkelsen, Nielsen, Tuchsen, \& Spangenberg, 2007).

In an analysis of the Danish National Work Injury Register for the 10-year period 1993-2002, it was shown that only 6.4\% of workplace accidents in Denmark involving HGV drivers were traffic related (cf. Shibuya, Cleal, et al., 2008). What emerges from a close analysis of the data is that the vast majority of occupational injuries experienced by HGV drivers are a result of activities relating to the loading and unloading of vehicles (Shibuya et al., 2010). This was also found to be the case in Washington State, USA, where the overall majority of injuries were non-vehicle related (Rauser et al., 2008). Of course, the volume of incidents tells us little of the relative risk and Danish accident data cannot further assist us here. Other sources can, however, clarify the extent of the problem. Data from the Danish Work Environment Survey of 2000 revealed that 5.8\% of all HGV drivers will experience an injury resulting in absence from work per annum, placing them at 0.5 percentage point above the average Danish worker (Mikkelsen, 2000). It has also been shown that Danish HGV drivers had significantly higher rates of hospital contact due to injury than the Danish male skilled/semi-skilled workforce in general (Shibuya, Hannerz, et al., 2008).

This risk in HGV drivers is, however, barely reflected in the approach to safety from within the industry. In a study of Danish transport companies it has been shown that the majority of the companies reported having an inactive or passive approach to workplace safety (Mikkelsen, Dyreborg, \& Spangenberg, 2003). To some extent, this can be accounted for by the nature of the industry and the fact that the vast majority of transport companies are small and medium sized enterprises, often lacking the resources to take a proactive and explicit stance towards safety (Dyreborg et al., 2008). In the USA, however we see that, even if measures to improve safety are in place, there are significant differences between employers and drivers when it comes to how they perceive the causes of accidents in the industry (Spielholz et al., 2008). Spielholz and colleagues found that, while employers attributed the causes of accidents to individual drivers, and saw the drivers' risks, perceptions and lack of attention as the main barriers for implementing injury prevention solutions, the drivers themselves pointed to causes related to environmental, technical and organisational factors. This differentiation of views regarding causes of, and solutions to, injuries and accidents calls for organisational dialogue and a more situational focus on workplace safety in heavy goods transport, a perspective that has been called for in previous studies (e.g. Shibuya et al., 2010). Moreover, the prioritisation of tasks versus safety and concepts of 'what ought to be done' in a transport company needs to be understood as part of the actual context of which workplace safety practices form a part (e.g. Edwards et al., 2014).

\subsection{Safety culture in HGV companies}

Ever since the concept of safety culture was first suggested it has mostly been used as a normative concept, referring to safety culture as a state that can be valued as 'good' or 'bad', i.e. as something that might be lacking (see Brinkmann, 2007; Edwards, Davey, \& Armstrong, 2013). This understanding presupposes an important role for top-management in the implementation and administration of good safety culture, in order to facilitate good safety practice or behaviour in a workforce (Glendon \& Stanton, 2000; Haukelid, 2008). Considering safety from the point of view of organisational culture, Glendon and 
Stanton suggest, for example, a distinction between functionalist (top-down) and interpretive (bottom-up) approaches. Following Waring (1996), they propose that "functionalist approaches assume that organizational culture exists as an ideal to which organizations should aspire" (Glendon \& Stanton, 2000: 194). This contrasts with interpretive approaches, which assume that organisational culture is an emergent complex phenomenon of social groupings with shared beliefs and values. This approach to culture has later been defined by Brinkmann (2007) as an anthropological conceptualisation. However, within this discipline there has always been a fundamental tension regarding whether the object being studied in the discipline was culture or cultures (cf. Wagner, 1975). A focus on cultures as something that can be associated with specific groups, provides us with a context for comprehending the way people behave in local contexts, a tradition that has, in recent years, become associated with cultural relativism, a position which is frequently connected with the work of Geertz (e.g. 1973).

In ethnographic work undertaken with HGV drivers it has been observed that individualism and independence are characteristic features of HGV culture (Agar, 1985; Grøn, 2008; Ouellet, 1994). Individualism refers to drivers working alone and taking responsibility for their own work, whereas independence refers to autonomy and being free to make one's own decisions. The truck drivers are understood to value their isolation and freedom, when comparing themselves to factory workers, for example, but also consider themselves to be marginalised and somewhat persecuted by the authorities (Agar, 1985; Ouellet, 1994) i.e. through regulations pertaining to HGV driving that are primarily implemented to improve traffic safety rather than the working environment of the drivers (Grøn, 2008). From the literature, it can be seen that HGV drivers share the ideas of both autonomy and interdependence in relation to their work with other blue-collar workers (i.e. Baarts, 2009; Gherardi \& Nicolini, 2002; Hass, 1977). Of course, being able to make your own decisions is inevitably connected to the nature of the work, as most HGV drivers work alone, but HGV drivers actually undertake several different forms of work, i.e. loading at distribution centres and unloading at department stores or other places. Therefore, while there is, perhaps, some truth in the representation of drivers as practicing work in independent ways, this does not necessarily tell the whole story. In a Danish context, Grøn has highlighted ways in which drivers actively seek out social relationships with people that they are not physically interacting with, e.g. seeking advice on the phone from friends and family in the business (Grøn, 2008). In fact, those that are most exposed to risk, measured by the extent to which they engage in loading and unloading activities, are also those most likely to engage in, and seek out, social relationships even if these are not exclusively with colleagues from the same company. Individualistic work practices are thus not to be understood as necessarily being in opposition to more collective aspects of the work, but are rather negotiated in relation to the actual task at hand (i.e. Baarts, 2009; McCabe, 2007).

With notable exceptions (e.g. Edwards et al., 2013; Gherardi \& Nicolini, 2000; Haukelid, 2008; Richter \& Koch, 2004) the majority of extant safety culture-based studies have tended to adopt or advocate a top-down approach - focusing on the organisation's ability to influence employees' values and attitudes through e.g. organisational structures and practices. This perspective on safety culture might, however, prove difficult to process in HGV companies, where tight control of the day-today behaviour of the staff is not possible. This is not to say that HGV management do not have avenues through which to influence their drivers or that there are no shared attitudes or values in these companies, but rather that communication and social interaction manifest themselves in ways which are sometimes overlooked in the questions posed by a conventional safety culture approach.

Drawing on a theoretical understanding of safety culture as practice (Brinkmann, 2007; Gherardi, 2009; Gherardi \& Nicolini, 2002; Gherardi, Nicolini, \& Odella, 1998), we aim to present an understanding of safety practice as influenced by group values and attitudes as well as organisational aspects. This is also in line with what Edwards and colleagues have labelled a synthesised concept of safety culture (Edwards et al., 2013), drawing attitudes and values and their interaction with an organisation's structures and systems, and the broader contextual setting into the analysis (Edwards et al., 2013: 77). Drawing on Lave and Wenger's concept of a 'community of practice' (Lave \& Wenger, 1991) the situated nature of knowledge is therefore essential to understanding safety culture as practice. There is consequently a close relationship between knowledge, the technology of practice and the culture of that practice (i.e. Gherardi et al., 1998). The safety culture of an organised system is understood to be an ongoing social construct, where many communities of practice contribute with often conflicting notions and practices of risk and safety (Gherardi et al., 1998). As such, safety is not regarded as being something that is communicated from leaders to employees only, but as a practice that is learned and perceived in the various work practices that constitute HGV driving.

\subsection{The purpose of the study}

This study focuses on an analysis of HGV drivers' and managers' differentiated understandings of risk and safety and its management in an organisational context. A situational focus involves viewing HGV drivers' working environment as being situated in the organisational structure, as well as in other social relationships with colleagues, former colleagues and others who shape their understandings and attitudes towards hazards and safe practices. Through an analytical focus on safety culture as practice, the study will identify values and attitudes, combined with organisational and technical elements, with a view to assessing how individualist or collectivist understandings of the drivers and the nature of their work impact on the working environment in the company. Through applying the notion of safety culture as practice, we might better understand why managers and drivers have different or similar views regarding reasons for risk taking in HGVs and, by implication, some insight into why and in which situations and settings, risk-taking behaviour occurs. 


\section{Methods}

\subsection{Study context}

The data we present in this article is derived from a study conducted within the transport division of a large company in Denmark (hereafter referred to as DANTRAN). The company distributes goods to supermarkets on a daily basis and employs over three hundred drivers in five different locations across the country. Our data has been obtained in two different company locations, one based in the capital area of Copenhagen (hereafter referred to as COPTRAN) and the other in the Jutland region (hereafter referred to as JUTTRAN). The study was part of a large-scale mixed methods intervention project across three different sectors focusing on the potential for increasing safety-related communication between management and workers in order to enhance safety culture and thereby prevent work accidents, a strategy in line with the aforementioned top-down perspective on safety culture. However, in the goods transport sector this perspective achieved little resonance. This was due, in part, to its absence within existing practice and also to widespread understandings in the organisation that HGV drivers' individually oriented work practices made them reluctant to accept safety messages from the management. Against this background we decided to adopt a more situational focus on safety communication and to collect data about attitudes and values in relation to health and safety, risk perception and communication.

\subsection{Data collection}

In this article we draw upon data from participant observations, semi-structured interviews and a questionnaire. Participant observation was conducted by all members of the research team, during which they spent a day or more with a particular driver, in total about 14 days. The researcher followed the driver throughout the working day in order to obtain a sense of the work involved, the potential risks in relation to loading and unloading and driving, and what, if any, safety practice was observable. Participant observation was distributed evenly between COPTRAN and JUTTRAN.

Semi-structured interviews were undertaken as individual interviews with the Transport Manager, the Dispatch Manager, Dispatchers and the Safety Manager at each site. Focus group interviews were conducted with drivers for the purpose of accessing shared perceptions and values, in line with our interest in identifying collectivist traits among this population (Hughes \& DuMont, 1993). A semi-structured interview guide was used in order for the researchers to be able to cover similar themes across company sites. In total we conducted 19 interviews, resulting in approximately $30 \mathrm{~h}$ of data material. In addition, a safety climate questionnaire (see Nielsen \& Mikkelsen, 2007) was distributed at both sites. The instrument used was a combination of safety climate scales supplemented with individual questions that addressed specific aspects identified in the previous interview study.

\subsection{Analysis}

This article is primarily based on interview data, since this data is most appropriate to the issues we are addressing. Two items from the questionnaires are drawn on, primarily for illustrative purposes. The data from the participant observation is used as a background for the study, as the information we gathered in this process and, in particular, the insight it provided into the working conditions to which drivers are exposed has been instrumental in forming our understanding of this context and the interpretations we apply to our qualitative data.

The interview data was coded using the qualitative data managing software Nvivo in accordance with the categories used in the interview guide. This was necessary in order to facilitate a process of collaborative coding, although each individual coder had opportunity to create new codes. Imposing this kind of rigour on the coding process obviously impedes the benefits that can be obtained from a more grounded approach (cf. Glaser, 1992). Nonetheless, the collaborative process also provides a source of validity, as using extracts from interviews identified and coded identically by more than one individual coder partially counteracts the subjective bias of individual interpretations.

Building a case around interview material is a process which is reliant on interpretation - on the ways in which we chose to treat and understand our data. Other interpretations might be possible, since interpretation is, of course, contingent on the questions which are posed. In the marshalling of our interview data, the issue of individualist versus collectivist attitudes and values were often used as explanations of behaviour and resistance to safety policies. These understandings are, however, also ambiguous and we have sought to explore this in relation to safety practice. This entails highlighting the interdependencies that actually exist among drivers and the interdependencies which, because of the assumption of independency and individualism among both management and drivers, are not fully exploited. Through doing so, we hope to demonstrate how an analytical focus on safety culture as a situated practice can highlight new avenues for a safer working environment in HGV drivers and the organisations in which they work. 


\section{Analysis}

\subsection{Accidents and injuries}

Setting out with the intention of looking at non-traffic related workplace safety among HGV drivers, our first task was to establish what kinds of incident led to injury in the view of the drivers and which factors they cited as contributing to the occurrence of these incidents. As mentioned, accident and injury data available from the Danish Working Authority indicated that falls from elevated areas and injuries resulting from the handling of heavy objects were the most likely cause of injuryrelated absence from work. This was supported in our interview data where, among the thirty or so drivers we interviewed, nearly all could recount an incident involving a fall and/or a body part being squashed or crushed as a result of manual handling. The extent to which these risks are actually perceived as risks worth taking seriously is, however, open to question, as the following quote from an interview indicates:

Interviewer: So you never had an accident when you were a driver?

COPTRAN Dispatcher: Never. Well, I've fallen off the lift and that kind of thing. But that's nothing.

Interviewer: Fallen off the lift? How?

COPTRAN Dispatcher: Yeah, it's just because you don't think, because things go quickly every now and then.

Interviewer: But you weren't injured?

COPTRAN Dispatcher: No, nothing serious, it was nothing.

This understanding of the risks as a part of the everyday practice involved in their work was prevalent among the drivers to which we spoke, and when they mentioned minor incidents they were referred to as 'being nothing' and as something that everybody experienced:

JUTTRAN Driver A: Yeah, I squashed my fingers fourteen days ago. So I was off work for a week.

Interviewer: What was it you...?

JUTTRAN Driver A: It was in the trailer and a container where one of the wheels was locked.

Interviewer: Ok. The wheel was locked....

JUTTRAN Driver A: Yeah, and so it turned right into the side of the trailer and I had my fingers between the side of the trailer and ...Uh ... it was (expletive) painful.

JUTTRAN Driver B: (Laughs) We've all done that.

In this quote Driver A is happy to recount this story as something of a joke, a joke that was instantly recognisable to the other drivers since, as Driver B observes, it is a shared experience. In both examples, the actual consequences are considered insignificant, but there was also recognition among the drivers that the consequences of the accidents could be more serious. In relation to falling off the lift, for example, we heard both first- and second-hand accounts of fractured ankles, fractured ribs, chronic knee injuries and back injuries. There was also awareness that consequences could be even more serious, since falls where the container (which weighs anything up to four hundred kilos) follows the driver off the lift could result in fatalities. This awareness of the potential risks involved in their work should not be overstated, however, as the predominant mode in which drivers considered risk and safety was through trivialisation and humour.

\subsection{The individualisation of risk and safety}

A collective sense of the risks to which they are exposed and an awareness of the potentially serious consequences that might result does not, it would seem, translate into a sense that safety is a serious problem for drivers. In order to appreciate why this might be the case, it is relevant to look at where the source of risk is located and who is responsible for safety. We asked the interviewees about what caused injuries in drivers, and they instantly referred to individuals as being responsible for injuries, as these resulted from ignorance or neglect:

Interviewer: What causes injuries?

JUTTRAN Driver C: It's this (points to head).

Interviewer: It's that?

JUTTRAN Driver C: Yeah, that's all it is. You're one-hundred percent aware of what you should and shouldn't do. And there's only two things. First, you're too stupid, because you work too fast or it's because you're ignorant (about safety). There's nothing else.

A tendency towards individualisation of the causes of risk was, again, quite common and by no means exclusive to the drivers:

COPTRAN Transport Manager: Accidents are often the result of stupidity. The man that takes three containers onto the lift or gets his fingers caught is just not thinking. They jump down from the lift even though they know they shouldn't.

It should be stressed that the Transport Manager at COPTRAN was extremely popular amongst the drivers and very concerned about the issue of safety. The above comment reflects frustration on his behalf and the sense that his ability to do anything about preventing accidents was severely limited and he did not equate drivers' practices to e.g. organisational 
practices. The sense of frustration expressed here is, nonetheless, very much based on a perception that risk and safety are individually determined. This however, brings to mind an important observation by Douglas and Wildavsky (1983: 93), that "[t]he selection of risks worth taking and avoiding is made by a process, not by a person". Something of this process was captured in the following quote from an interview:

Interviewer: Are you sometimes forced to break safety rules?

COPTRAN Driver A: You probably do.

Interviewer: Do you need to?

COPTRAN Driver A: I don't know if you need to, but you probably do every now and then.

COPTRAN Driver B: The question is which safety rules...

COPTRAN Driver C: Yeah, I'd like to know that too, which safety rules you break.

COPTRAN Driver B: There aren't really any safety rules as such.

COPTRAN Driver C: You have safety shoes on when you're at work right?

COPTRAN Driver B: Yeah that, and we should use ear plugs and... I mean, the company takes safety seriously but there aren't any special rules about how you handle containers or how you handle the truck or anything like that.

When asked why there were not any specific rules in relation to the handling of containers, the Transport Manager at COPTRAN stated that he could not see any point in implementing rules which he could not enforce. His point here is that, given that the drivers work alone and, at least when unloading goods at department stores, surveillance is more or less impossible. Moreover, he felt that to introduce such rules was tantamount to treating his workforce like children, preferring instead to treat them as mature individuals with an awareness of their own responsibility with regard to safety - this being in accordance with his idea of risk (and safety) as an individual responsibility.

As we have seen, drivers are just as inclined towards individualising the reasons for risk taking and safety practices. The difference, however, concerns the issue of control. Individualising risk is, for management, an acknowledgement of their limitations in respect to risk and safety. For drivers, in contrast, the individualisation of risk serves to preserve an idea of control with regard to one's own working practice. Working safely is possible as long as one is consciously aware, and takes responsibility for, its implementation. This establishes the boundaries of control, but also serves to cultivate a trivialisation of risk and safety, since when things go wrong it is nearly always considered because someone has done something stupid. Both views are founded upon a belief that it is the very nature of the work (task independency), and the workplace culture which determines what can and cannot be done with respect to safe working practices. In this way it is possible to see how the impulse to establish a sense of control can serve as an obstacle to learning and change (cf. Argyris, 1994: 343). The question is therefore, whether these attitudes and values in relation to self-determinacy and individual judgement tell the whole story.

From the questionnaire provided to the drivers, two items are of particular relevance to our analysis here, namely 'which available sources of information they (the drivers) used' and the 'levels of trust accorded to these different sources' (see Fig. 1).

As can be seen in Fig. 1, personal experience is by far and away the most used and trusted source of information. This is to be expected and, in itself, does not say anything about the attitudes of drivers. What is more striking however, is that while individual representatives of management are accorded relatively high levels of trust, this is not reflected in the extent to which they are perceived as an actual source of information. Colleagues, in contrast, score relatively highly as a source of information about risks, although they are not trusted to the same extent as individual representatives of management. This suggests two aspects. Firstly, the results seem to indicate that management's assumptions with respect to drivers are reflected in the extent to which they actively disseminate information about safety. However, inasmuch as colleagues appear as the second most used source of information concerning risks, the results also suggest that drivers actually seek out and use colleagues as a source of information. Referring reasons for injuries and unsafe practices to one's own reason and judgement does not mean that the advice and opinion of others is not valued. In the following sections we turn to an analysis that goes beyond simplistic explanations of their safety practice as individualistic.

\subsection{HGV drivers and latent interdependencies}

In the type of work undertaken by the drivers in DANTRAN, a number of clearly observable interdependencies exist between drivers and other groups, such as dispatchers and warehouse staff. However, the case for claiming interdependencies between drivers is less immediately obvious. To make the case it is also necessary to clarify what is usually understood by the term (e.g. Thompson, 1967). Physical proximity is, for example, one dimension of task interdependency that is clearly absent in the work of HGV drivers. In invoking the possibility of considering the work of HGV drivers as involving interdependencies, our focus is directed more towards the sharing of skills and resources that do not presuppose physical proximity. As we will show, such sharing of skills and resources already exists; however, what is absent is any active support of this sharing at the organisational level. This point can be illustrated by looking to a specific work-related safety problem that emerged from our data. 


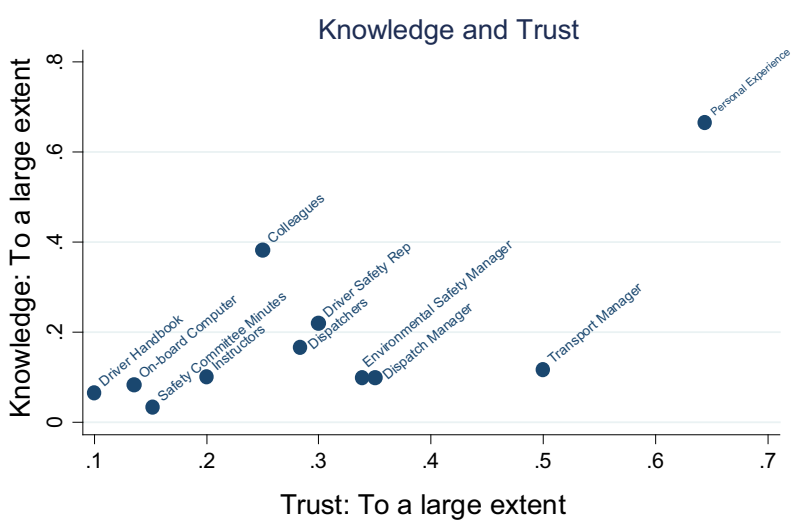

Fig. 1. We asked respondents: (1) To what extent do you trust information obtained from the following sources? (2) Where do you obtain information concerning the risks in your work? Responses were provided on a five point Likert-scale. The $x$-axis indicates the proportion of respondents that indicated that they "To a large extent" trusted the specified source of information, and the $y$-axis indicates the proportion of the respondents that indicated that they "To a large extent" used the specified source of information to acquire knowledge.

\subsection{Loading and unloading}

Aside from viewing individual stupidity as an important cause of injuries, the drivers referred to the working conditions in loading and unloading areas as poor and a causal factor for risk of injury. The working conditions were also perceived to have direct consequences for driver safety, as the company safety officer describes in the following:

COPTRAN Safety Officer: We can see too that accidents happen at the places where the conditions are bad more than the places where the loading and unloading areas are good. There can be accidents there every now and then, but the majority is due to something connected to (poor) loading and unloading conditions.

Attributing blame in this manner also allows management to abrogate responsibility for safety, since the conditions to which drivers are exposed, are ostensibly the responsibility of the stores where they make their deliveries. The HGV company can, and does, make demands of the stores, but the extent to which these demands are absolute is qualified by the fear of offending and/or losing customers. While it could be argued that the company could do more in this respect, the managers and drivers agree that the fault lies with the stores:

COPTRAN Driver D: But still our. . loading and unloading it's at the stores. That's the biggest problem we've got and they don't do anything.

COPTRAN Driver E: They don't do anything.

In addition to holes in tarmac, typical examples of poor conditions the drivers stated were uneven surfaces, poor access, inappropriate ramps, limited manoeuvrability and poor housekeeping. However, while it is true that working conditions in loading and unloading areas was perceived as a risk to worker safety, it is also the case that these risks were, from the point of view of individual drivers, not something to which they felt vulnerable. This relates to our earlier observations about the individual responsibility and management that the drivers take in relation to risk:

COPTRAN Driver D: The thing is, when you drive a permanent route, you know where every hole is and you don't worry about them.

Interviewer: So drivers without permanent routes have...

COPTRAN Driver F: ... the biggest chance of getting injured..

COPTRAN Driver D: Yeah, because those of us who drive a permanent route, we know, we've been in all those holes. We know, it's like second nature, 'there's that hole, and there's that hole over there'.

For the drivers, workplace safety is a practical issue that they manage by drawing on knowledge gained from their personal experience 'of being there'. Knowledge of how to manage risk is situated in the actual tasks that they are involved in and standardised safety rules appear to lose their relevance. As the preceding quote indicates, there is a distinction among drivers between those that drive permanent routes and those that drive different routes on different days. Acquiring a permanent route is a mark of distinction as they are only allocated after one has been employed by the company for a certain length of time. Consequently, the least experienced drivers are exposed to varying; often dangerous, working conditions that prevent them from obtaining the kind of situated knowledge about risks to which the more experienced have access. This combination of inexperience and poor working conditions is widely recognised as a problem within the organisation among drivers and managers alike. 


\subsubsection{Sharing knowledge}

Prior to our collaboration DANTRAN tried to implement a system whereby experienced drivers could document the safety-related issues at particular stores. This information would then be collated and made available to all new drivers, or drivers operating a new route. However, the project was largely unsuccessful, a fact for which it was possible to find a variety of explanations:

Interviewer: How about in relation to, if there's an accident or what we call a near-miss? Is that something that the drivers share with each other?

JUTTRAN Safety Manager: No, it's. . especially our drivers I think, they're really bad at sharing their experience. We had that project too, that project with....we talked a lot about that there were many stores with poor conditions for unloading, so we gave them some forms that they should fill out. It's the same that they're doing at COPTRAN. They're much better at.

Drivers at COPTRAN had a slightly different take on this:

COPTRAN Driver B: At some point there was focus on the loading areas. I don't know what happened to that. COPTRAN Driver A: No, I think that's been filed under 'forgotten'.

COPTRAN Driver B: It was something to do with where responsibility should be placed.

COPTRAN Driver C: I thought it was something that (name) (Safety Manager) did.

COPTRAN Driver B: Yeah, but if it was the stores. .

COPTRAN Driver A: Yeah, but I would put it this way, that the company has often taken a load of good initiatives but it's just. ...they fall apart, they don't get followed up.

COPTRAN Driver B: And it would cost a lot of money, if it was going to be completely right.

In this instance, the COPTRAN drivers refer to the company being at fault rather than the drivers, and they thereby identify organisational practice as the reason for risk behaviour in the company. This is interesting because the gap between these two accounts suggests a disagreement about why unsafe practices prevail; that it does not only have to do with the drivers' self-perceived stupidity or interdependence. The sense making (or shared understanding) among drivers is that the organisation's espoused interest in improving working conditions for drivers only applies to the extent that it does not require any financial commitment for the company. Both accounts can be considered as attempts to contextualise failure, a process in which blame is located externally and, by implication, so too the responsibility for enacting changes. At the same time, in the experience of the JUTRAN Safety Manager, drivers are not sharing experiences on near-misses or risks with each other, which suggests a lack of communication between the drivers. Formal safety learning in the organisation thus seems to be low.

That said, the analysis of the drivers' interviews shows that drivers have priorities other than safety and they are quite clear about this. In the following account a driver describes how he calculates safety in relation to maintaining the pace of work:

COPTRAN Driver G: I don't use the lift any more than I absolutely have to. Like I say, I would rather not take one step more than necessary at work. For every step I take, I get less for myself right. ...that's how I think all the time (laughs). It's calculated in millimetres.

Yet it is also the case that the way of working described by this driver, though involving conscious and continual flouting of safe practice does have its benefits from a management perspective:

COPTRAN Driver G: That's also why our boss (Transport Manager) doesn't mind if you work the way I do. Normally a Boss would say 'take it easy' but there's never any problems with my route. I'm like sometimes an hour ahead of schedule. The customers are crying with joy.

Customer satisfaction is obviously an essential imperative in any service industry and, as such, employees who positively contribute to this parameter are highly valued. The fact that customer satisfaction is, in this case, based on an essential elasticity with regard to what is, and what is not, safe practice goes some way to explaining why management is inclined to characterise their drivers as individualists. Through individualising the reasoning pertaining to risk taking and the responsibility of safety serves, if only by default, to legitimise the fact that certain employees can enhance productivity by potentially exposing themselves to danger (cf. Rasmussen \& Svedung, 2000). At the same time, the notion of HGV drivers as independent workers forms an integral part of the concept of drivers being free and responsible for their own work. However, this does not imply yet another example of management compromising safety for the sake of productivity; the commitment to this way of doing things is not something which is actively encouraged or explicitly rewarded. Rather, the point is that this bias towards perceiving drivers as individualists, can lead to management overlooking other aspects of HGV driving; i.e. organisational safety culture practices including communication and sharing of information and advice with which the drivers engage. This fact has, in turn, consequences for the ways in which attempts to improve driver safety are approached. 


\section{Discussion}

The analysis has highlighted issues of risk perception and responsibility and the nature of knowledge sharing in a HGV company in relation to non-traffic related workplace safety. The drivers are fully aware of the potential risks involved in their work, but in the communication with colleagues these are trivialised, and in the interviews they are referred to as 'nothing'. This trivialisation is also linked to an individualised understanding of how risks should be handled. This individualisation of risk is found in numerous industries that employ a semi-skilled male workforce (i.e. Grøn, 2008; Nordlöf, Wiitavaara, Winblad, Wijk, \& Westerling, 2015). In our case, a perception of drivers as being essentially individualistic was used by management as an argument not to implement safety rules, since they would probably not be followed and, even if implemented, they could not, due to the remote location of the drivers, actually be enforced. In contrast, for the drivers, the individualistic approach served to establish a sense of control with the risks that they encounter on an everyday basis. The analysis has also revealed alternative, more collectivistic tendencies among the drivers and also to organisational and technical reasons for the prevailing safety practices. The fact that attempts to formally include drivers' experiences in risk management had failed did not mean that these experiences were not shared and used through other channels. There was, at least, a willingness to share experiences and, with regard to inexperienced drivers working new routes each day, the lack of situated experience among new drivers was a matter of concern among the more experienced drivers. These informal interdependencies among the drivers did, however, prove difficult for management to exploit at the organisational level. Accordingly, at this level, the interdependencies between drivers remained latent, an underexploited resource which, if activated, could contribute to enhanced levels of safety.

The data presented in Fig. 1 captures something of the paradoxical situation observed in the course of this project. For, while the management was accorded relatively high levels of trust, they provided little in the way of information, than the least trusted sources. After personal experience, it was colleagues who provided most in the way of information regarding risk and safety, yet colleagues were not trusted to the same extent as representatives of management. The relative position of colleagues here can, perhaps, be explained by the informality that marked their exchanges, though it should also be recognised that it was this very informality which influenced the degree to which they were utilised as a resource. Recognition of this fact might serve to enhance the organisation's attempts to improve safety, enabling solutions founded on a contextually-based understanding of how information is actually exchanged. Doing so would bestow greater credibility to communication regarding risk and safety and, as such, be of benefit to both management and drivers.

It should be stressed, having highlighted various possibilities for how management might improve safety, that DANTRAN has consistently shown a commitment to improving working conditions for its drivers. Drivers too, frequently favourably compared the company in relation to other companies within the industry. As such, they can be considered as an atypical example in the Danish transport industry. The fact that their efforts to improve safety have been hampered by a failure to recognise the contextual nuances in the social practice of drivers is not, therefore, based upon apathy or disregard. Rather, the problem lies with the fact that the way in which management characterises the workforce colours their perception of the problems with which they are dealing, blinding them to other characteristics that might be usefully drawn upon. Highlighting these contingencies can serve as a first step towards better safety practises.

The tendency towards implementing the de-contextualised, top-down solutions which we have identified in our data, has been prevalent in safety culture research. Of course, if there is one thing that researchers working with safety culture are agreed upon, it is that there is very little agreement about what safety culture actually is (cf. Clarke, 2000; Edwards et al., 2013; Guldenmund, 2000; Hale, 2000; Pidgeon, 1998; Richter \& Koch, 2004). Appreciating that workplace safety does not allow for the apparent luxury of cultural relativism, since it is an ideal which we strive towards, top-down solutions to safety problems might seem pertinent. However, as this study has highlighted, a focus on contextual factors - and their impact on safety (as suggested by Edwards et al., 2014) or on safety as practice (as suggested by Gherardi, 2009; Gherardi \& Nicolini, 2002) - seems to open up for other equally relevant perspectives of analysis and intervention in the area of non-traffic related safety in HGV transport.

The essence of our argument regarding how a safety culture perspective might enhance work safety among HGV drivers is that there is a need to understand workplace cultures on their own terms. The analysis has highlighted a need to understand safety as a practice that is socially constructed even in HGV companies. Considering safety culture as a situated practice should not, however, lead to a form of cultural relativism, but rather to a practical approach to obtaining insight about what contributes to safe practice in a given setting. In order to achieve this balancing act, we need to carefully consider the methods we use to extract context. Our own approach, using qualitative interviews, was appropriate since we wanted to explore the understanding of safety in relation to hierarchical practices in the company. In this sense, we have not sought to go beyond the specific context that we have encountered. Subsequent research in this area might benefit from a more systematic approach to the analysis of social relationships among HGV drivers and how this impacts on the practice of safety in a given company. This should provide further opportunities for extracting general information from specific settings in a way which remains faithful to the nuanced and contextually rooted way in which workers practice and communicate safety.

\section{Conclusion}

The analysis has revealed understandings of risk as prevalent but trivialised, and notions of safety management as one's own responsibility as part of DANTRAN's situated safety practices. In addition, knowledge of how to manage risks in everyday 
practice has not only been shown to be primarily related to personal experiences, but also to advice and examples from fellow drivers and leaders. The analysis has also revealed pockets of collectivist practice among the drivers that can be utilised in order to improve knowledge sharing and situational safety practices. Consequently, non-traffic related safety practices, in this case the loading and unloading of vehicles, occurs in the grey zone of organisational safety management; organisational safety initiatives are initiated, but the management sees few opportunities to enforce safety initiatives, let alone safety rules, and therefore safety practice is left to the individual driver. The analysis implies a need for a new model for safety initiatives based on more collectivist albeit informal safety culture practices in HGV driving. The starting point for this might be the professional and cultural community among drivers emerging from their interdependent and collectivist practices.

\section{Acknowledgements}

We are grateful to the workplaces and individuals who accepted to participate in this research. The project was supported by the Danish Working Environment Research Fund, grant no. 2-2004-03.

\section{References}

Adams-Guppy, J., \& Guppy, A. (2003). Truck driver fatigue risk assessment and management: A multinational survey. Ergonomics, 46, 763-779.

Agar, M. (1985). The dilemmas of independent trucking, independents declared.Washington, DC: Smithsonian Institution Press.

Argyris, C. (1994). Initiating change that preserves. Journal of Public Administration Research and Theory, 4, $343-355$.

Baarts, C. (2009). Collective individualism: The informal and emergent dynamics of practicing safety in a high-risk work environment. Construction Management and Economics, 27, 949-957.

Brinkmann, S. (2007). Culture as practices: A pragmatist conception. Journal of Theoretical and Philosophical Psychology, 27, $192-212$.

Bunn, T. L., Slavova, S., Struttmann, T. W., \& Browning, S. R. (2005). Sleepiness/fatigue and distraction/inattention as factors for fatal versus nonfatal commercial motor vehicle driver injuries. Accident Analysis and Prevention, 37, 862-869.

Campagne, A., Pebayle, T., \& Muzet, A. (2004). Correlation between driving errors and vigilance level: Influence of the driver's age. Physiology E' Behavior, 80, $515-524$

Clarke, S. (2000). Safety culture: Under-specified and overrated? International Journal of Management Reviews, 2, 65-90.

Douglas, M., \& Wildavsky, A. (1983). Risk and culture: An essay on the selection of technological and environmental dangers.Berkeley, CA: University of California Press.

Dyreborg, J., Andersen, L. P., Carstensen, O., Cleal, B., Grytnes, R., Grøn, S., ... Spangenberg, S. (2008). FAIS - Forebyggelse af Alvorlige Arbejdsulykker gennem Intervention i Sikkerhed og Sikkerhedskultur (Prevention of serious accidents through intervention in safety and safety culture).København: Det Nationale Forskningscenter for Arbejdsmiljø.

Edwards, J. R. D., Davey, J., \& Armstrong, A. K. (2013). Review. Returning to the roots of culture: A review and re-conceptualization of safety culture. Safety Science, 55, 70-80.

Edwards, J. R. D., Davey, J., \& Armstrong, A. K. (2014). Profiling contextual factors which influence safety in heavy vehicle industries. Accident Analysis and Prevention, 73, 340-350.

Geertz, C. (1973). The interpretation of cultures.New York: Basic Books.

Gherardi, S., Nicolini, D., \& Odella, F. (1998). What do you mean by safety? Conflicting perspectives on accident causation and safety management in a construction firm. Journal of Contingencies and Crisis Management, 6(4), 202-213.

Gherardi, S., \& Nicolini, D. (2000). The organizational learning of safety in communities of practice. Journal of Management Inquiry, 9, 7-18.

Gherardi, S., \& Nicolini, D. (2002). Learning a trade: A culture of safety in practice. Organization, 9, $191-223$.

Gherardi, S. (2009). Introduction: The critical power of the 'practice lens'. Management Learning, 40, $115-128$.

Glaser, B. (1992). Basics of grounded theory analysis.Mill Valley, CA: Sociology Press.

Glendon, A. I., \& Stanton, N. A. (2000). Perspectives on safety culture. Safety Science, 34, 193-214.

Grøn, S. M. F. (2008). Sikkerhedskultur og arbejdspraksis hos lastvognschauffører - En fortælling om frihed og tanketorsk Ph.d. - Afhandling (in English; safety culture and work practice among heavy vehicle drivers, PhD dissertation). Det Nationale Forskningscenter For Arbejdsmiljø og Institut for Miljø, Samfund og Rumlig Forandring, Roskilde Universitetscenter.

Guldenmund, F. (2000). The nature of safety culture: A review of theory and research. Safety Science, 34, $215-257$.

Hale, A. (2000). Culture's confusions. Safety Science, 34, 1-14.

Hannerz, H., Mikkelsen, K. L., Nielsen, M. K., Tuchsen, F., \& Spangenberg, S. (2007). Social inequalities in injury occurrence and in disability retirement attributable to injuries: A 5 year follow-up study of a 2.1 million gainfully employed people. BMC Public Health.

Hass, J. (1977). Learning real feelings: A study for high steel ironworker's reactions to fear and danger. Work and Occupations, 4, 147ff.

Haukelid, K. (2008). Theories of (safety) culture revisited-An anthropological approach. Safety Science, 46, 413-426.

Hughes, D., \& DuMont, K. (1993). Using focus groups to facilitate culturally anchored research. American Journal of Community Psychology, 21(6), 775-806.

Irvine, C. H. (1967). Driver falls while mounting or dismounting cap over engine tractor trailer cabs (Rep. no. Final project report nr. 66-8).Hopkinton, MA: Liberty Mutual Company Research Centre Publications.

Lave, J., \& Wenger, E. (1991). Situated learning. Legitimate peripheral participation. Cambridge University Press.

Leigh, J. P., Waehrer, G., Miller, T. R., \& Keenan, C. (2004). Costs of occupational injury and illness across industries. Scandinavian Journal of Work, Environment E' Health, 30(3), 199-205.

McCabe, D. (2007). Individualization at work? Subjectivity, teamworking and anti-unionism. Organization, 14(2), 243-266.

Mikkelsen, K. L., Dyreborg, J., \& Spangenberg, S. (2003). Måling af fremdriften i virksomheder for visionen: Dødsulykker og andre alvorlige ulykker, samt skader blandt unge 18-23-årige.Copenhagen: Arbejdsmiljøinstituttet og CASA.

Mikkelsen, K. L. (2000). Arbejdsmiljø i tal: Arbejdsulykker og arbejdsmiljø i Danmark 2000. (Eng: The working environment in numbers: Injuries at work and the working environment in Denmark 2000) (p. 2002). Copenhagen: Arbejdsmiljøinstituttet.

Nordlöf, H., Wiitavaara, B., Winblad, U., Wijk, K., \& Westerling, R. (2015). Safety culture and reasons for risk taking at a large steel-manufacturing company: Investigating the worker perspective. Safety Science, 73, 126-135.

Nielsen, K. J., \& Mikkelsen, K. (2007). Predictive factors for self-reported occupational injuries at 3 manufacturing pants. Safety Science Monitor, 11(11).

Ouellet, L. (1994). Pedal to the metal, the work lives of truckers.Philadelphia, PA: Temple University Press.

Pidgeon, N. (1998). Safety culture: Key theoretical issues. Work E' Stress, 12, 202-216.

Rasmussen, J., \& Svedung, I. (2000). Proactive risk management in a dynamic society.Karlstad, Sweden: Swedish Rescue Services Agency.

Rauser, E., Foley, M., Bonauto, D., Edwards, S., Spielholz, P., \& Silverstein, B. (2008). Preventing injuries in the trucking industry, focus report 1997-2005. Technical report number 90-17-2008. Dept. of Labour and Industries.

Richter, A., \& Koch, C. (2004). Integration, differentiation and ambiguity in safety cultures. Safety Science, 42, 703-722.

Shibuya, H., Cleal, B., \& Mikkelsen, K. L. (2008). Work injuries among drivers in the goods-transport branch in Denmark. American Journal of Industrial Medicine, 51, 364-371. 
Shibuya, H., Hannerz, H., Mikkelsen, K., Cleal, B., \& Gubba, L. (2008). Hospital contacts due to injuries among male drivers working for road goods-transport contractors in Denmark. International Journal of Occupational Medicine and Environmental Health, 21, 59-66.

Shibuya, H., Cleal, B., \& Kines, P. (2010). Hazard scenarios of truck drivers' occupational accidents on and around trucks during loading and unloading. Accident Analysis and Prevention, 42, 19-29.

Smith, C. K., \& Williams, J. (2014). Work related injuries in Washington State's Trucking Industry, by industry sector and occupation. Accident Analysis and Prevention, 65, 63-71.

Spielholz, P., Cullen, J., Smith, C., Howard, N., Silverstein, B., \& Bonauto, D. (2008). Assessment of perceived injury risk and priorities among truck drivers and trucking companies in Washington State. Journal of Safety Research, 39(6), 569-576.

Taylor, A. H., \& Dorn, L. (2006). Stress, fatigue, health, and risk of road traffic accidents among professional drivers: The contribution of physical inactivity. Annual Review of Public Health, 27, 371-391.

Thompson, J. D. (1967). Organizations in action.New York: McGraw-Hill.

Wagner, R. (1975). The invention of culture.Chicago, IL: The University of Chicago Press.

Waring, A. E. (1996). Safety management systems.London: Chapman \& Hall. 